\title{
Student Ratings of Teaching Effectiveness: An Importance - Performance Analysis (IPA)
}

\author{
Nik Rozina @ Nik ‘Azyyati Nik Jaafar
}

\author{
Department of Commerce, Kota Bharu Polytechnic, Malaysia; nikazyyati@gmail.com
}

Zarina Mohd Noor

Department of Commerce, Kota Bharu Polytechnic, Malaysia; zarinamnoor70@gmail.com

Mazlina Mohamed

Department of Commerce, Kota Bharu Polytechnic, Malaysia; Corresponding Author. mazlinapkb@gmail.com

Doi:10.5901/jesr.2016.v6n3p33

\begin{abstract}
The aims of this study were to identify effective teaching attributes using the Students' Evaluation of Educational Quality (SEEQ) questionnaire and evaluate students' level of satisfaction using the Importance-Performance Analysis (IPA) technique. Data were collected from three groups of students enrolled in three different courses i.e. Business Ethics (BE), Business Presentation Skills (BPS) and Integrated Marketing Communications (IMC) at a Malaysian polytechnic. The total number of students involved were sixty seven and each course was taught by a different lecturer. A shorter version of the SEEQ questionnaire (22 items) was used to assess the teaching attributes according to students' perceived satisfaction and importance. A five-point Likert-type scale ranging from "very dissatisfied" to "very satisfied" was used to measure students' perceived satisfaction. Similarly, a five-point Likert-type scale ranging from "not important at all" to "very important" was used to measure students' perceived importance. By plotting the importance-performance rating of each lecturer in the four quadrants of the Importance-Performance Matrix, for the BE course, gaps were found in nine attributes related to motivational and pedagogical factors. Similarly, gaps were also found for BPS and IMC courses where these gaps were related to instructor's friendliness, accessibility and instructor-student interaction. For all three courses, students were satisfied with the given assignments which they agreed facilitated their learning. The majority of the students also expressed satisfaction on the lecturers' knowledge of the courses. The findings of this study have identified the less satisfactory teaching attributes and these could be used to modify teaching strategies to enhance students' learning. Thus it is recommended that Malaysian polytechnics use the dual approach i.e. the SEEQ questionnaire and the IPA technique to assess teaching effectiveness.
\end{abstract}

Keywords: teaching effectiveness, students' evaluation of educational quality (SEEQ), importance-performance analysis (IPA)

\section{Introduction}

Research has shown that teacher quality and instructional expertise influence student achievement (e.g. Borman \& Kimball, 2005; Muijs, \& Reynolds, 2002). Other contributing factors include content and pedagogical knowledge (Hill, Rowan, \& Ball, 2005; Kahan, Cooper, \& Bethea, 2003). Borman dan Kimball (2005) stated that teacher evaluation is an important mechanism for improving teaching and learning while Danielson and McGreal (2000) and Beerens (2000) identified two primary aims for evaluating teachers: (i) professional growth, and (ii) accountability. Teacher evaluations normally incorporate single or limited data source (e.g. student feedback) or multiple data sources and evaluators (e.g. student achievement, peer assessment).

There are currently 34 polytechnics under the purview of the Ministry of Higher Education, Malaysia. The main role of these public institutions is to produce graduates at the semi-professional and middle executive levels to meet the industry's needs. Polytechnics offer full-time and part-time programs at diploma levels in the fields of engineering, commerce and services. Some selected polytechnics also offer advanced diploma and degree programs in collaboration with local universities (Department of Polytechnic Education, 2016).

It is common practice in all polytechnics that students complete an in-house ratings instrument in each academic semester as a means of measuring teaching effectiveness. The use of this instrument facilitates a direct and convenient feedback to lecturers so that they can readily improve their teaching practices, thus providing students with better 
learning experiences. Ten items in the questionnaire were loosely adapted from two validated instruments widely used in higher education: The Students' Evaluation of Educational Quality (SEEQ) and The Course Experience Questionnaire (CEQ). An additional item is on the use of the English language as the medium of instruction. There is also an openended question soliciting students' feedback on how to improve the course. Ratings are based on a scale of 1 (strongly disagree) to 5 (strongly agree). The questionnaire is normally administered to the students during the fourth week of the semester. Data collected is then analysed by the respective Heads of Program/Department and disseminated to the lecturers. However, the use of the present in-house ratings instrument to evaluate teaching effectiveness has raised a number of concerns, particularly with respect to its reliability and validity, coverage of the dimensions of quality teaching, and effective method to communicate the results to the lecturers. Thus this study was conducted using a combination of the SEEQ questionnaire and the IPA technique to demonstrate their potential as a replacement for the present in-house ratings instrument for evaluating teaching effectiveness.

\section{Literature Review}

\subsection{Teaching Effectiveness and Student Rating}

Student ratings of instruction (SRI) are widely used in institutions of higher education/universities as a measure of teaching effectiveness (Dresel \& Rindermann, 2011). Other common acronyms found in literature are SRT (student rating of teaching), SET (student evaluation of teaching), SETE (student evaluation of teaching effectiveness) and SEF (student evaluation of faculty). According to Harvey (2003), collecting students' evaluations of teaching serves two purposes: (i) gaining internal information used for guiding improvements, and (ii) gaining external information for future students and other interested parties. In measuring the quality of the delivery of instruction, some research findings have shown that students are in the best position to provide feedback (Coughlan; 2004; Kwan, 1999). There have been many studies of student ratings to evaluate teaching effectiveness. Hill, Lomas, and MacGregor (2003) investigated students' perception of quality education and discovered that students appreciated lecturers who are well organized and knowledgeable in their subjects. Similar results were obtained by Voss and Gruber (2006) where students prefer teachers who are knowledgeable, enthusiastic, approachable, and friendly. Geall (2000) meanwhile found teacher attributes appreciated by the students were: giving feedback during classes and in assignments, and being helpful and friendly. Similarly, a survey of first year undergraduates by Zimitat (2006) found that students regard the following teacher attributes as the most important aspects of good teaching: (i) good in giving explanations, (ii) approachable, (iii) enthusiasm for the subject matter, and (iv) giving feedbacks.

There are also numerous research that investigate the variables that may correlate with student ratings of teachers. A study by Beran and Violato (2005) showed that laboratory work received higher ratings than lectures or tutorials. The researchers argued that hands-on application of theory gave greater satisfaction, and thus higher ratings for instruction. Cashin (1992) stated that instructors teaching certain disciplines tend to receive higher student ratings than instructors in other disciplines. The author further stated that arts and humanities courses normally get the highest ratings. Mathematics, engineering and physical sciences courses get lower ratings probably due to the perceived difficulty of these courses. Marsh (1984) however found that the instructor, and not the course, as the primary determinant of students' ratings. This finding was based on a study where the researcher categorized student ratings data into four categories: (i) the same instructor teaching the same course but in different semesters, (ii) the same instructor teaching a different course, (iii) different instructors teaching the same course, and (iv) different instructors teaching different courses.

Other researchers like Braskamp and Ory (1994) and McKeachie (1979) argued that higher ratings were given by students to elective courses as compared to required courses. According to Marsh and Dunkin (1997), teachers were more likely to receive higher ratings in classes where students had a prior interest in the subject matter. Students who exceled in their courses were also found to have given high ratings when evaluating teacher effectiveness (Greenwald, 2002). Research on the relationship between course workload/subject-matter difficulty and student ratings had produced mixed results. Marsh and Roche (2000) found a positive and direct relationship between workload and student ratings, contradicting findings by Centra (1993) and Greenwald (2002) who reported lower student ratings when the workload was high.

A number of studies on teaching effectiveness has been carried out by local researchers. Khairudin and Islam (2000) conducted a study at Ungku Omar Polytechnic to investigate the use of Nominal Group Technique (NGT) in facilitating improvements in teaching and learning practices. Their study identified 3 specific areas for teacher 
improvement, namely content expertise (e.g. in-depth knowledge of subject-area), instructional design skill (e.g. innovative teaching methods) and delivery design skill (e.g. good communication skills). A discrepancy analysis was used by Wan Kamaruddin and Ibrahim (2010) in identifying the competencies of polytechnic technical lecturers that needed enhancement. Using a sample of 401 technical lecturers from five Malaysian polytechnics, the authors discovered that the level of knowledge and the level of performance of these competencies were not on par with the level of perceived importance. The study also revealed that 12 professional competencies and six general competencies needed enhancement.

A study of students' perceptions of effective teaching and learning in business universities was carried out by Abdul Hamid \& Pihie (2004). Their findings suggested that the lecturers exhibited qualities in all the following constructs under study, namely the lecturers' characteristic, teaching methodology, and course relevance. Another study of teaching effectiveness was carried out by Chua and Kho (2015) at a local Teacher Education Institute. The survey data revealed that the five teacher attributes which had high scores were related to the ability in conducting teaching learning activities, providing awareness on the development of human capital, commitment towards teaching and learning, monitoring and giving feedbacks, and motivating students to pursue learning activities. Mat Daud and Abu Kassim (2011) examined student rating of teaching effectiveness at International Islamic University, Malaysia. The questionnaire that they used managed to identify lecturers that needed in-service training. Other interesting findings include the difficulty in keeping class interested and getting students' participation in class activities. At Universiti Putra Malaysia, Safavi, Abu Bakar, Ahmad Tarmizi and Alwi (2012) conducted a study to investigate the perceived utility of ratings information of 1139 academics. Some of the findings revealed that the majority of the lecturers were in agreement on these points: 1) instructional performance should be evaluated by students, and 2) student ratings were taken seriously. On the suitability of the questionnaire, some of the suggestions by the lecturers include the following: 1) a revision of the questionnaire items, and 2) allowing of additional items related to their courses, specifically concerning course objectives and teaching methods.

\subsection{The Students' Evaluation of Educational Quality (SEEQ) Course Survey}

The SEEQ instrument was developed by Marsh (1982) and is used to obtain student feedback on teaching quality and effectiveness. SEEQ questionnaire comprises thirty five closed-ended statements grouped into nine dimensions of teaching: (i) learning/academic value e.g. course intellectually challenging/stimulating, (ii) instructor enthusiasm e.g. dynamic/energetic in conducting course, iii) organization/clarity e.g. course materials well prepared/carefully explained, (iv) group interaction e.g. students encouraged to participate in class discussions, (v) individual rapport e.g. instructor friendly towards individual students (vi) breadth of coverage e.g. introduce background/origin of ideas/concepts, (vii) assignments/readings e.g. availability of homework etc. to contribute understanding of subject, (viii) examinations Igrading e.g. availability of feedback from exams/graded materials and (ix) workload/difficulty e.g. relative course difficulty (very easy,medium,very hard). Supplemental items including open-ended statements can be included where required. A five-point Likert-type scale ranging from "very poor" to "very good" is used for each of the thirty-five items. The reliability and validity of the SEEQ questionnaire have been confirmed by various researchers (e.g. al-Muslim \& Arifin, 2015; Coffey \& Gibbs, 2001).

\subsection{Importance-Performance Analysis (IPA)}

Martilla and James (1997) introduced Importance-Performance Analysis (IPA) as a marketing tool in identifying and evaluating customer satisfaction and expectation based on perceived importance and performance. The IPA technique (also known as Quadrant Analysis) has two dimensions: importance and performance. According to Hendricks, Schneider \& Budruk (2004), IPA involves three steps: (i) identifying a list of attributes to evaluate, (ii) rating the attributes according to customers' perceived satisfaction and importance, and (iii) plotting the importance-performance rating on a two dimensional grid. IPA basically consists of four quadrants of the I-P grid where the vertical axis represents the expected service quality (level of importance) and the horizontal axis represents the perceived level of performance (satisfaction). (see Fig.1). 


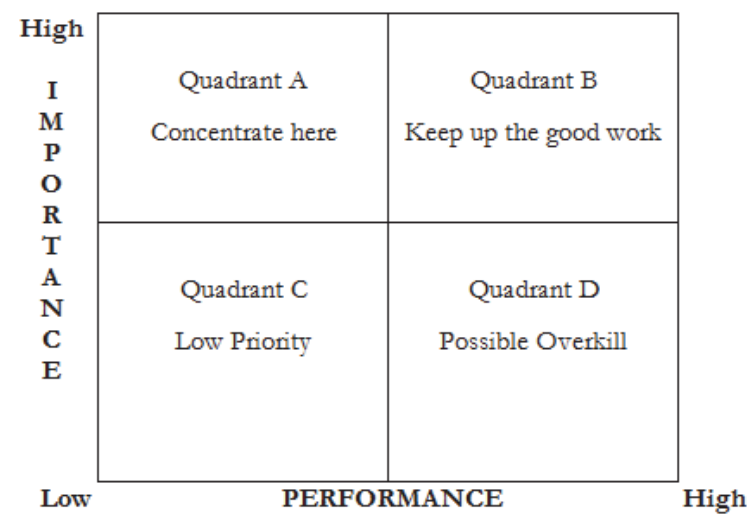

Figure 1: Importance-Performance Analysis (IPA) Matrix

With reference to Fig.1. Quadrant A (Concentrate Here) represents high importance degree of attributes but low performance degree (low satisfaction). Quadrant B (Keep Up The Good Work) represents attributes of both high importance and high performance. Quadrant C (Low Priority) contains attributes that are considered to be less important and have low performance degree. Quadrant $D$ (Possible Overkill) comprises of attributes that are perceived as of relatively low importance but of high performance. Analysis of data will indicate: (i) attributes needing immediate improvement (Quadrant A); (ii) attributes to be retained i.e. major strengths (Quadrant B); (iii) attributes needing less attention (Quadrants $C$ and D). IPA, due to its simplicity and effectiveness, has been widely used as a managerial or research tool in various fields such as tourism (e.g. Su, 2013), health services (e.g. Gonçalves, Pinto, Batista, Pereira, \& Ambrosano, 2014), recreation (e.g. Gill, Bowker, Bergstrom \& Zarnoch; 2010), business and management (e.g. Riviezzo, de Nisco, \& Napolitano, 2009) and sports research (e.g. Rial, Rial, Varela \& Real, 2008) .

In the education field, the literature has shown many studies done by reseachers such as Mourkani, and Shohoodi (2013), O' Neill and Palmer (2005), and Joseph, Yakhou, and Stone (2005). Tóth, Jónás, Bérces, and Bedzsula (2013) surveyed students in 5 different business courses to gain an insight concerning students' perceptions of quality and to gain a deeper understanding about the factors that influence student satisfaction and dissatisfaction. A similar study was conducted by Kanchana and Triwanapong (2011) to investigate the students' perceptions on the importance and satisfaction levels on the quality of educational services provided by the faculty. IPA specifically has been used in a number of studies in relation to student evaluation of teaching effectiveness. Alberty and Mihalik (1989) used IPA as an evaluative technique for adult learners whilst Attarian (1996) employed IPA to evaluate teaching effectiveness in a university outdoor program. Other studies using IPA to evaluate teaching effectiveness were carried out by Yu and Ming (2012) and Siniscalchi, Beale, and Fortuna (2008).

Local studies in the education field have also been conducted by a number of researchers. Ramli, Latifah and $\mathrm{Ng}$ (2008) used IPA to assess the improvements in delivering its services to students at an Open University in Malaysia whilst Abidin and Daud (2012) used the IPA to compare the personality traits of business and technical graduates. In another study, Abdul Hamid, Islam, and Abd Manaf (2014) investigated graduates' employability skills as perceived by employers. The researchers discovered that 13 students' attributes fell into the improvement quadrant of the IPA matrix and the biggest gap was found in communication skills. Yusoff (2010) investigated the factors that influence student satisfaction in the Malaysian private educational environment and ranked the perceived importance of these factors. Results from this study revealed the following teacher attributes as influencing students' satisfaction: approachability of teaching staff, level of difficulty of course content, teachers' teaching ability, friendliness of teachers, and professionalism of teachers. Teacher attributes considered important by students' were teaching ability, level of knowledge, and consistency of teaching.

\section{Problem Statement}

According to Marsh (2007), 'student evaluation of teaching instruments should be designed to measure separate components of teaching effectiveness, and support for both the content and the construct validity of the multiple 
dimensions should be evaluated'. The use of a locally developed instrument to evaluate teaching effectiveness has raised a number of concerns: (i) lack of any proof of reliability or validity, (ii) the existence of variable(s) known not to be linked to student performance, (iii) rather limited in scope i.e. insufficient number of items to cover all possible dimensions of quality teaching, and (iv) no standard and effective method to communicate the results to the teachers. Even though the main purpose of this instrument is to gather data to help enhance the teaching performance, it only has eleven items to cover various aspects of teaching quality and arguably has never been tested for its reliability and validity. There are also methodological weaknesses in the analysis and presentation of the collected data where there is little standardization on how the analysed data is conveyed to the teachers and how improvements in teaching can be made. Many administrators are not familiar with research on student ratings of teachers leading to some teachers perceiving the evaluation exercise as merely fulfilling an administrative obligation. Thus this study was carried out with two major aims: (i) to use the Students' Evaluation of Educational Quality (SEEQ) questionnaire in place of the in-house ratings instruments, and (ii) to highlight the use of Importance-Performance Analysis (IPA) as a management tool to measure teaching effectiveness. The combined use of the SEEQ questionnaire and IPA technique will make student rating of teaching effectiveness at Malaysian polytechnics a valid procedure.

\section{Research Objectives}

This study attempts to highlight the use of the SEEQ instrument and the IPA technique in identifying students' perceptions of teaching effectiveness. More specifically, this study aims to:

1) Identify effective teaching attributes using the SEEQ instrument and,

2) Analyze the data for the importance and performance values of each attribute using the IPA technique

\section{Methodology}

\subsection{Sample and Data Collection Procedure}

Data were collected at a selected polytechnic located on the east coast of peninsular Malaysia. The respondents consisted of students from two diploma programs i.e. Business Studies and Marketing. (Table 1). All the questionnaires were administered at the end of the lectures and collected in-situ.

Table 1. Respondents' Characteristics

\begin{tabular}{|c|c|c|c|}
\hline No. Program \& No. of Students & Course & Credit Hour & Assessment \\
\hline 1. Diploma in Business Studies $(n=29)$ & Business Ethics (BE) & 3 & CA \& FE \\
\hline 2. Diploma in Marketing $(n=21)$ & Business Presentation Skills (BPS) & 3 & CA only \\
\hline 3. Diploma in Marketing $(n=17)$ & Integrated Marketing Communications (IMC) & 3 & $\mathrm{CA} \& \mathrm{FE}$ \\
\hline
\end{tabular}

\subsection{Research Instrument}

This study utilized a modified version of the original SEEQ questionnaire. Shorter versions of SEEQ had been employed by several researchers without compromising on its reliability and validity (e.g. Coffey \& Gibbs, 2001; Bol, Sáiz, \& Pérez, 2013). According to Richardson (2005), even though the SEEQ instrument has been used in many countries, its adoption has to suit different educational settings. A shortened version of the standard SEEQ is desirable for rapid acquisition of data and avoiding the risk of item non-response. For the purpose of this study, items from the original SEEQ questionnaire were modified to reflect the rating of specific instructors based on students' perceived satisfaction (performance) and expectations (importance).

In brief, the survey instrument used in this study consisted of five main parts: Part A was on the demography of students (gender, course, cumulative grade point average (CGPA) and achievement in the English language subject in the Malaysian Certificate of Education examinations). Parts B and D each consisted of twenty two items adapted from the SEEQ questionnaire where respondents were asked to rate the degree to which they agreed with each item description. A 5-point Likert scale in Part B measured the performance level of 'very satisfied' (5) to 'very dissatisfied' (1) attributed to each item in that section. Similarly, the 'importance' of each attribute in Part D was measured using a 5-point Likert scale ranging from 'very important' (5) to 'very unimportant' (1). Part C of the questionnaire consisted of three items 
on the usage of the English language in the classroom. A 5-point Likert scale measured the frequency of the English language used by the teachers ( $5=$ always to $1=$ never). Part $D$ of the survey instrument was an open-ended question soliciting students' opinion on how to improve the teaching effectiveness.

Cronbach's alpha coefficients were computed to check the internal consistency of the subscales in Parts B and D of the questionnaire. Reliability coefficients ranging from 0.86 to 0.92 (Part B) and 0.88 to 0.94 (Part D) were found, indicating fairly reliable subscales. According to Marsh (1987), previous research on the consistency of student's ratings has shown reliability estimates (coefficients alpha) ranging from 0.87 to 0.98 .

\subsection{Data analysis}

The Statistical Package for the Social Sciences (SPSS) program version 20.0 was used to analysis the data. Descriptive analysis was used to determine (i) the mean score of importance and performance ratings, and (ii) the grand means of importance and performance attribute scores. The grand means for attribute importance and performance were used for plotting $x$-axis and $y$-axis crosshairs in the IPA matrix. To compare the importance and performance of teaching effectiveness, the mean score of importance and performance ratings were then plotted on the IPA matrix where the $y$ axis represented respondents' importance rating of each attribute and the $x$-axis represented the corresponding perceived performance rating of the attributes. There are four main approaches in determining crosshairs and dividing the IPA matrix into quadrants for interpretation of the findings: the scale mid-point (e.g. Chapman,1993), one unit above the scale mid-point (Novatorov, 1997), the grand means of the scales (e.g. Deng, Chen \& Pei, 2008) and the median of the scales (e.g. Huang \& Beaman, 2005). In this study, the grand means of each of the courses were used to determine the crosshairs: BE $(4.52,4.59)$, BPS $(4.53,4.85)$ and IMC $(4.43,4.46)$. This approach was taken because of the high ratings on both importance and performance of the measures and if the scale mean (i.e. 3) was used as the crosshair, all the 22 items would be located in quadrant B of the IP matrix.

\section{Results and Discussion}

\subsection{Demographic Characteristics of the Respondents}

A total of sixty seven students from two study programs and undertaking three different courses completed the questionnaire survey (Table 1). Each course was taught by three different lecturers. Twelve of the students were males (18\%). The majority of the students (>70\%) obtained grades $\mathrm{C}$ and below in the English language national examinations. For the three courses of BE, BPS and IMC, more than $80 \%$ of the students obtained grades $B$ and above in their final semester examinations.

\subsection{English as a Medium of Instruction}

Three items in Part $\mathrm{C}$ of the questionnaire surveyed students' perception on the usage of the English language as a medium of instruction. An analysis of the data showed that more than half of the respondents (72\%) indicated that the lecturers often used English when giving lectures whilst $96 \%$ stated that English was used during tutorial sessions and when undertaking assignments. These results were to be expected since the Malaysian polytechnic curriculum is in English and all related teaching and learning activities were to be carried out in English. However, probably because of the low English proficiency of the students, some respondents had suggested using both English and Malay languages for a better understanding of the subject. These suggestions were obtained from Part $E$ of the questionnaire which asked students the following question: In your opinion, how can the teaching for this course be enhanced?

\subsection{Mean Ratings of Importance and Performance Attributes}

Table 2 shows the mean scores of the twenty two teaching attributes for each course in relation to Importance and Performance. All items had a mean above the scale mid-point and the grand means of importance $(\mathrm{I})$ and performance $(P)$ were $(P=4.52, I=4.59),(P=4.53, I=4.85)$ and $(P=4.43, I=4.46)$ for $B E, B P S$ and IMC courses respectively. For $\mathrm{BE}$, three items ( $\mathrm{F}, \mathrm{N}$ and $\mathrm{T})$ in the performance rating had the highest mean score of 4.69 whilst the lowest score was 4.31 for item C (I have learned something which I consider valuable). For the importance rating, item N (the instructor was friendly towards individual students) had the highest mean score of 4.79 and the lowest mean score of 4.34 was 
recorded by items A (I have learned and understood the subject materials of this course) and $\mathrm{C}$ (I have learned something which I consider valuable). Similarly for BPS, the highest mean scores in the performance rating was 5.0 for items $\mathrm{N}$ (the instructor was friendly towards individual students) and $\mathrm{V}$ (the tutorials were helpful in clarifying the materials presented in lectures). The lowest mean score was 4.33 for item $\mathrm{G}$ (the instructor begins lessons with a review of previous lessons). The highest mean score in the importance rating was 5.0 for items $E$ (the instructor was enthusiastic about teaching the course) and R (the instructor is knowledgeable on the subject matter). Item B (I have found the course intellectually challenging and stimulating) recorded the lowest mean score of 4.57 . The highest mean score in the performance rating for IMC was 4.69 for item $\mathrm{V}$ (the tutorials were helpful in clarifying the materials presented in lectures) whilst the lowest mean score was 4.13 for item $F$ (the instructor's style of presentation held my interest during class). For the importance rating, two items $L$ (students were encouraged to ask questions and were given meaningful answers) and $\mathrm{O}$ (the instructor was adequately accessible to students during office hours or after class) recorded the highest mean score of 4.63. The lowest mean score of 4.25 was recorded for item $M$ (the instructor fostered an atmosphere of mutual respect).

In summary, for both BE and BPS courses, the mean scores of twelve teaching attributes (importance) were found to be higher than the respective performance teaching attributes. For IMC, the mean scores of eight teaching attributes (importance) were found to be higher than the respective performance teaching attributes. A further examination highlighted two teaching attributes (items no. $\mathrm{H}$ and $\mathrm{L}$ ) had lower mean scores for 'performance' as compared to 'importance' mean scores for all three courses. The difference in the mean scores of 'importance' and 'performance' shows the existence of a teaching effectiveness gap as perceived by the students. Teaching attributes considered most important were instructor's friendliness, enthusiasm, knowledge, accessibility and instructor-student interaction. Two unsatisfactory teaching attributes (items no. $\mathrm{H}$ and $\mathrm{L}$ ) and common to all three lectures, should be given special attention by the respective lecturer to improve his/her teaching effectiveness.

Table 2. Means in Importance and Performance Ratings

\begin{tabular}{|c|c|c|c|c|c|c|}
\hline & \multicolumn{2}{|c|}{$\mathrm{BE}$} & \multicolumn{2}{|c|}{ BPS } & \multicolumn{2}{|c|}{ IMC } \\
\hline $\begin{array}{l}\text { Item Teaching Attribute } \\
\text { No. }\end{array}$ & Mea & Mea & Mea & Mean (I) & le & Mean (I) \\
\hline A I have learned and understood the subject materials of this course. & 4.55 & 4.34 & 4.95 & 4.95 & 4.56 & 4.44 \\
\hline B I have found the course intellectually challenging and stimulating. & 4.34 & 4.38 & 4.38 & 4.57 & 4.50 & 4.44 \\
\hline C I have learned something which I consider valuable. & 4.31 & 4.34 & 4.90 & 4.90 & 4.31 & 4.50 \\
\hline D My interest in the subject has increased as a consequence of this course. & 4.59 & 4.48 & 4.43 & 4.62 & 4.56 & 4.56 \\
\hline E The instructor was enthusiastic about teaching the course. & 4.34 & 4.59 & 4.95 & 5.00 & 4.44 & 4.38 \\
\hline F The instructor's style of presentation held my interest during class. & 4.69 & 4.59 & 4.95 & 4.67 & 4.13 & 4.38 \\
\hline G The instructor begins lessons with a review of previous lessons. & 4.45 & 4.45 & 4.33 & 4.86 & 4.25 & 4.38 \\
\hline H The instructor presents material in an organized and coherent way. & 4.34 & 4.72 & 4.86 & 4.90 & 4.25 & 4.44 \\
\hline I The instructor makes use of examples and illustrations in his/her explanatic & 4.62 & 4.59 & 4.90 & 4.90 & 4.44 & 4.38 \\
\hline J $\quad$ Course materials were well prepared. & 4.41 & 4.66 & 4.90 & 4.90 & 4.44 & 4.38 \\
\hline K Students were encouraged to participate in class discussions. & 4.48 & 4.62 & 4.81 & 4.86 & 4.44 & 4.44 \\
\hline L Students were encouraged to ask questions and were given meaningful answers. & 4.48 & 4.62 & 4.38 & 4.62 & 4.31 & 4.63 \\
\hline M The instructor fostered an atmosphere of mutual respect. & 4.41 & 4.66 & 4.81 & 4.90 & 4.50 & 4.25 \\
\hline $\mathrm{N}$ The instructor was friendly towards individual students. & 4.69 & 4.79 & 5.00 & 4.95 & 4.38 & 4.56 \\
\hline O The instructor was adequately accessible to students during office hours or after class. & 4.76 & 4.62 & 4.43 & 4.86 & 4.25 & 4.63 \\
\hline $\mathrm{P} \quad$ The instructor adequately discussed current developments in the field. & 4.52 & 4.55 & 4.52 & 4.67 & 4.38 & 4.38 \\
\hline Q The instructor presented the background or origin of ideas/concepts developed in class. & 4.48 & 4.66 & 4.95 & 4.90 & 4.44 & 4.38 \\
\hline $\mathrm{R}$ The instructor is knowledgeable on the subject matter. & 4.52 & 4.66 & 4.71 & 5.00 & 4.56 & 4.44 \\
\hline S Instructor summarize the main points in this course. & 4.72 & 4.69 & 4.43 & 4.95 & 4.44 & 4.50 \\
\hline $\mathrm{T}$ Assignments were well designed and facilitated learning in this course. & 4.69 & 4.69 & 5.00 & 4.90 & 4.63 & 4.56 \\
\hline U Lectures and tutorials were well integrated. & 4.48 & 4.69 & 4.95 & 4.86 & 4.63 & 4.50 \\
\hline V The tutorials were helpful in clarifying the materials presented in lectures. & 4.45 & 4.66 & 5.00 & 4.86 & 4.69 & 4.50 \\
\hline Grand Mean & 4.52 & 4.59 & 4.53 & 4.85 & 4.43 & 4.46 \\
\hline
\end{tabular}

Standard Deviation (s.d) :

for BE, s.d ranged from 0.435 to 0.783 (performance) \& 0.412 to 0.733 (importance)

for BPS, s.d ranged from 0.426 to 0.763 (performance) \& 0.442 to 0.730 (importance)

for IMC, s.d ranged from 0.479 to 0.806 (performance) \& 0.512 to 0.806 (importance) 


\subsection{Distribution of Teaching Attributes in the IPA Matrix}

Table 3 shows the distribution of the teaching effectiveness measures in each quadrant of the IP matrix for the three courses.

Table 3. Distribution of Teaching Effectiveness Measures According to Courses

\begin{tabular}{cccc}
\hline Quadrant & Business Ethics (BE) Business Presentation Skills (BPS) Integrated MarketingCommunications (IMC) \\
\hline $\begin{array}{c}\text { A } \\
\text { Concentrate Here }\end{array}$ & $\mathrm{E}, \mathrm{H}, \mathrm{J}, \mathrm{K}, \mathrm{L}, \mathrm{M}, \mathrm{Q}, \mathrm{U}, \mathrm{V}$ & $\mathrm{O}, \mathrm{G}, \mathrm{S}$ & $\mathrm{C}, \mathrm{L}, \mathrm{N}, \mathrm{O}$ \\
\hline $\begin{array}{c}\text { B } \\
\text { Keep Up The Good Work }\end{array}$ & $\mathrm{F}, \mathrm{I}, \mathrm{N}, \mathrm{O}, \mathrm{P}, \mathrm{R}, \mathrm{S}, \mathrm{T}$ & $\mathrm{A}, \mathrm{C}, \mathrm{E}, \mathrm{H}, \mathrm{K}, \mathrm{M}, \mathrm{N}, \mathrm{Q}, \mathrm{R}, \mathrm{T}, \mathrm{U}, \mathrm{Q}, \mathrm{V}$ & $\mathrm{D}, \mathrm{S}, \mathrm{T}, \mathrm{U}, \mathrm{V}$ \\
\hline $\begin{array}{c}\text { C } \\
\text { Low Priority }\end{array}$ & $\mathrm{B}, \mathrm{C}, \mathrm{G}$ & $\mathrm{B}, \mathrm{D}, \mathrm{L}, \mathrm{P}$ & $\mathrm{F}, \mathrm{G}, \mathrm{H}, \mathrm{P}$ \\
\hline $\begin{array}{c}\text { D } \\
\text { Possible Overkill }\end{array}$ & $\mathrm{A}, \mathrm{D}$ & $\mathrm{F}, \mathrm{I}, \mathrm{J}$ & $\mathrm{A}, \mathrm{B}, \mathrm{E}, \mathrm{I}, \mathrm{J}, \mathrm{K}, \mathrm{M}, \mathrm{Q}, \mathrm{R}$ \\
\hline
\end{tabular}

Data in Table 3 is then presented in the IPA matrix (Figs. 2, 3 and 4). The $y$-axis represents respondents' importance rating of each attribute and the $x$-axis represents the perceived performance on the same attributes. From Fig. 2 (and Table 3), it could be seen that nine items ( $E, H, J, K, L, M, Q, U, V)$ fall into the 'Concentrate Here' quadrant and need immediate action. On closer inspection, these nine items are related to the motivation and pedagogical factors which if left unchecked, could continuously undermine the quality of teaching. Good and Brophy (1994) state that effective teachers have the ability to set achievable goals and present content so that students can learn.

Figs. 3 and 4 (and Table 3 ) show three $(\mathrm{O}, \mathrm{G}, \mathrm{S}$ ) and four (C, L, N, O) items in the 'Concentrate Here' quadrants respectively. Some of these items which require improvement belong to the following factors: instructor's friendliness, accessibility and instructor-student interaction. According to Wubbels, Levy and Brekelmans (1997), effective teachers build strong relationships with their students in a caring and supportive classroom environment.

The 'Keep Up The Good Work' quadrant represents attributes of both high importance and high performance. From Figs. 2, 3 and 4 (also Table 3), there are eight, thirteen and five items, respectively in this quadrant. Items that fall into this quadrant suggest the strength and the good work of the lecturers. The 'Low Priority' quadrant consist of attributes that are considered to be less important while the 'Possible Overkill' quadrant contains attributes that are overly emphasized by the lecturers. For example, nine attributes (items $A, B, E, I, J, K, M, Q, R$ ) in the 'Possible Overkill' quadrant for IMC course represent teaching aspects where the lecturer concerned appears to put too much emphasis. It is however, difficult to make any inferences regarding the attributes contained in the 'Low Priority' and 'Possible Overkill' quadrants because of the different nature of the three courses and the dissimilarities in the teaching styles of the lecturers involved in this study.

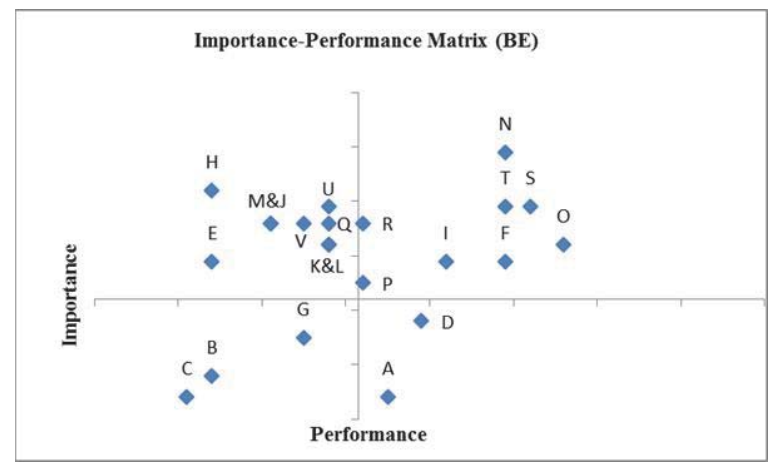

Figure 2. Importance-Performance Matrix for BE Course 


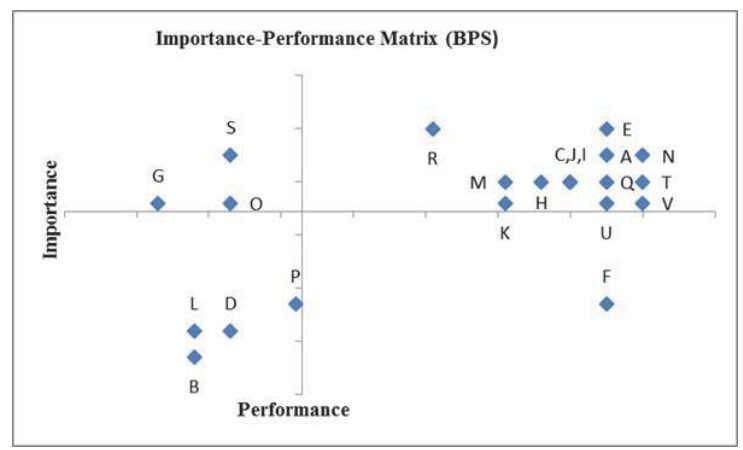

Figure 3. Importance-Performance Matrix for BPS Course

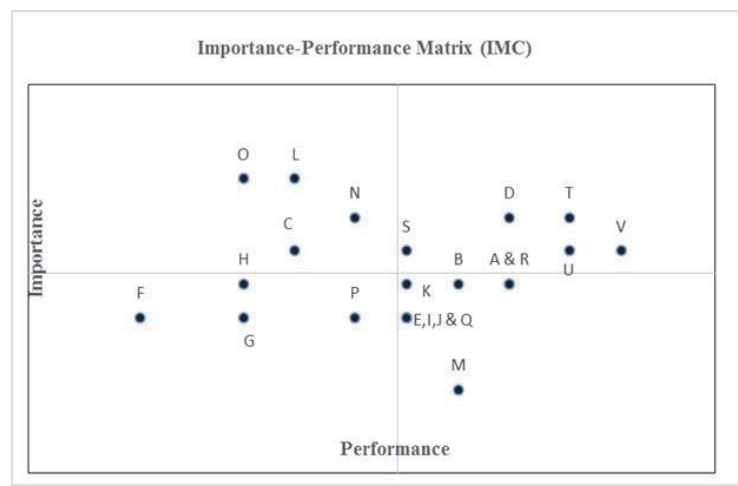

Figure 4. Importance-Performance Matrix for IMC Course

\section{Conclusion and Recommendations}

This study demonstrates the effective use of both SEEQ and IPA for teaching evaluation. Based on students' feedback, results obtained from both these instruments would help lecturers to improve the quality of their teaching by providing insights into the strengths and weaknesses of their teaching practice. The use of an instrument such as SEEQ has eliminate concerns regarding the reliability and validity of data when evaluating teaching effectiveness. The IPA tool, on the other hand enables the lecturers to refine their teaching methods for greater student satisfaction and achievement. By using this dual approach, lecturers can modify their teaching strategies by improving the less satisfactory teaching attributes. Both of these instruments are relatively easy to administer and interpret, making it useful not only to the lecturers but also to the administrators. According to Babbage (2002), effective teachers are those that knew how to challenge and encourage their students, apart from demonstrating enthusiasm for the content.

The results of this study suggest that students' evaluation is a practical approach in measuring teaching effectiveness. However several researchers have also forwarded a number of recommendations to improve instruction when using student evaluations. Centra (1994), for example stated four conditions to be fulfilled by teachers and administrators to improve instruction: (i) teachers learn something new and important from the results, (ii) teachers and administrators value the new information, (iii) teachers and administrators understand how to use the results and how to make improvements, and (iv) teachers and administrators must be motivated to make changes and improvements. Emery, Kramer and Tian (2003) meanwhile suggest using multiple sources of data such as the instructor's teaching portfolio, students' achievements, and peer evaluation. It is also recommended that the evaluation results are disseminated to the students and any follow-up actions are taken within a reasonable time after the students have rated the teaching. A combined used of the SEEQ and IPA tools to gather and analyze data on teaching effectiveness can assist teachers to improve teaching and thereby student learning. 


\section{References}

Abdul Hamid, J., \& Pihie, Z. A. (2004). Students' Perception of the Quality of Teaching and Learning in Business Studies Programs. Pertanika J. Soc. Sci. \& Hum, 12(1), 71-86.

Abdul Hamid, M.S., Islam, R., \& Abd Manaf, N.H. (2014). Malaysian Graduates' Employability Skills Enhancement: An Application of the Importance-Performance Analysis. Journal for Global Business Advancement, 7(3), 181 - 197.

Abidin, N., \& Daud, S. (2012). Personality Traits: Business versus Technical Graduates. Communications of the IBIMA. Available February 12, 2016 from http://www.ibimapublishing.com/journals/CIBIMA/2012/747338/747338.pdf

Alberty, S \& Mihalik, B.J. (1989). The Use of Importance- Performance Analysis as an Evaluative Technique in Adult Education. Evaluation Review. 13(1). 33-44.

al-Muslim, M., \& Arifin, Z. (2015). The Usability of SEEQ in Quality Evaluation of Arabic Secondary Education in Malaysia. International Education Studies, 8(3), 202-211.

Attarian, A. (1996). Using Importance-Performance Analysis to Evaluate Teaching Effectiveness. In R. Watters (Ed.), Proceedings for the 9th International Conference on Outdoor Recreation (pp. 145-150). Pocatello, ID: Idaho State University Press.

Babbage, K. (2002). Extreme teaching. Lanham, MD: The Scarecrow Press.

Beerens, D. R. (2000). Evaluating teachers for professional growth: Creating a culture of motivation and learning. Thousand Oaks, CA: Corwin Press, Inc.

Beran, T., \& Violato, C. (2009). Student Ratings of Teaching Effectiveness: Student Engagement and Course Characteristics. Canadian Journal of Higher Education, 39(1), 1-13.

Bol, A., Sáiz, M.C., \& Pérez, M. (2013). Validation of Test Teaching Activity in Higher Education. Aula Abierta, 41(2), 45-54.

Borman, G. D., \& Kimball, S. (2005). Teacher quality and educational equality: Do teachers with higher standards-based evaluation ratings close student achievement gaps? Elementary School Journal, 106, 3-20.

Braskamp, L.A., \& Ory, J.C. (1994). Assessing Faculty Work. San Francisco: Jossey-Bass Publishers.

Cashin, W. E. (1992). Student ratings: The need for comparative data. Instructional Evaluation and Faculty Development, 12(2), 1-6.

Centra, J. (1993). Reflective faculty evaluation. San Francisco: Jossey-Bass.

Centra, J.A. (1994, April). Current Issues in Evaluating and Improving College Teaching. Paper presented at the annual meeting of the American Educational Research Association (AERA), Atlanta, GA.

Chapman, R.G. (1993). Non-simultaneous relative importance-performance analysis: Meta results from 80 college choice surveys with 55,276 respondents. Journal of Marketing for Higher Education. 4(1-2): 405-422.

Chua, L.C., \& Kho, R.K.H. (2015). What Do Teacher Education Students Tell Us about the Teaching Performance of English Language Lecturers? The English Teacher, XLIV(1), 13-22.

Coffey, M., \& Gibbs, G. (2001). The Evaluation of the Student Evaluation of Educational Quality Questionnaire (SEEQ) in UK Higher Education. Assessment and Evaluation in Higher Education, 26, 89-93.

Coughlan, A. (2004) Evaluating the learning experience: the case for a student feedback system. Quality Promotion Office, National University of Ireland, Maynooth.

Danielson, C., \& McGreal, T. (2000). Teacher evaluation to enhance professional practice. Alexandria, VA: Association for Supervision and Curriculum Development.

Deng, W.J., Chen, W.C., \& Pei, W. (2008). Back-propogation neural network based importance-performance analysis for determining critical service attributes. Expert Systems with Evaluations. 34, 1115-1125.

Department of Polytechnic Education. (2016). Retrieved 10 January, 2016 from http://www.politeknik.edu.my/portalbpp/index.asp

Dresel, M., \& Rindermann, H. (2011). Counseling university instructors based on student evaluations of their teaching effectiveness: A multilevel test of its effectiveness under consideration of bias and unfairness variables. Research in Higher Education, 52(7), 717-737.

Emery, C.R., Kramer, T.R., \& Tian, R.G. (2003). Return to academic standards. Quality Assurance in Education, 11(1), $37-46$.

Geall, V. (2000). The expectations and experience of first year students at City University of Hong Kong. Quality in Higher Education. $6(1), 77-89$

Gill, J.K., Bowker, J. M., Bergstrom, J.C. \& Zarnoch, S.J. (2010). Accounting for Trip Frequency in Importance-Performance Analysis. Journal of Park and Recreation Administration, 28(1), 16-35.

Gonçalves, J., Pinto, A. ,Batista, M. , Pereira, A. \& Ambrosano, G. B. (2014) Importance-performance analysis: Revisiting a tool for the evaluation of clinical services. Health, 6(5), 285-291.

Good, T., \& Brophy, J. (1994). Looking in classrooms (6th ed.). New York:HarperCollins

Greenwald, A. (2002). Constructs in student ratings of instructors. In H. I. Braun \& D. N. Jackson (Eds.), The role of constructs in psychological and educational measurement (pp. 277-297). New York: Erlbaum.

Harvey, L. (2003). Student feedback. Quality in Higher Education, 9(1), 3-20.

Hendricks, W. W., Schneider, I. E., \& Budruk, M. (2004). Extending importance-performance analysis with benefit-based segmentation. Journal of Park and Recreation Administration, 22(1), 53-74.

Hill, Y., Lomas, L. \& MacGregor, J. (2003). Students' perceptions of quality in higher education, Quality Assurance in Education, 11(1), $15-20$.

Hill, H. C., Rowan, B., \& Ball, D. L. (2005). Effects of teachers' mathematical knowledge for teaching on student achievement. American Educational Research Journal, 42(2), 371-406. 
Huang, T.C., \& Beaman, J. (2005, May). Importance-Performance Analysis: The Need to Bridge Solitudes for its Effective Use. Paper Presented at the Eleventh Canadian Congress on Leisure Research, Nanaimo, B.C.

Joseph, M., Yakhou, M., \& Stone, G. (2005). An Educational Institution's Quest for Service Quality: Customers' Perspective. Quality Assurance in Education, 13(1), 66-82.

Kahan, J., Cooper, D., \& Bethea, K. (2003). The role of mathematics teachers' content knowledge in their teaching: A framework for research applied to a study of student teachers. Journal of Mathematics Teacher Education, 6(3), 223-252.

Kanchana, R., \& Triwanapong, S. (2011). Identifying the Key Quality Improvement of Undergraduate Engineering Education - Using Importance-Performance Analysis. The 9th International and National Conference on Engineering Education (INCEE9). May 4-5, 2011, Hilton Phuket Acadia Resort \& Spa, Karon Beach, Phuket, Thailand.

Khairudin, N.A., \& Islam, R. (2000). TQM in Business Education in Malaysia: A Case Study based on the Applicability of Nominal Group Technique. Journal of International Business and Entrepreneurship, 8(1), 103 - 124.

Kwan, K.P. (1999). How fair are student ratings in assessing the teaching performance of university teachers? Assessment \& Evaluation in Higher Education, 24(2), 181-195.

Marsh, H. (1982). SEEQ: A Reliable, Valid, and Useful Instrument in Collecting Students' Evaluations of University Teaching. British Journal of Educational Psychology, 52, 77-95.

Marsh, H. W. (1984). Students' evaluations of university teaching: Dimensionality, reliability, validity, potential biases, and utility. Journal of Educational Psychology, 76, 707-754.

Marsh, H. W. (1987). Students' evaluations of university teaching: Research findings, methodological issues, and directions for future research. International Journal of Educational Research, 11(3), 253-388.

Marsh, H.W. (2007). Do university teachers become more effective with experience? A multilevel growth model of students' evaluations of teaching over 13 years. Journal of Educational Psychology, 99(4), 775-790.

Marsh, H. W., \& Dunkin, M. J. (1997). Students' evaluations of university teaching: A multidimensional perspective. In R. P. Perry \& J. C. Smart (Eds.), Effective teaching in higher education: Research and practice (pp. 241-320). New York: Agathon Press.

Marsh, H. W., \& Roche, L. A. (2000). Effects of grading leniency and low workload on students' evaluations of teaching: Popular myth, bias, validity, or innocent bystanders? Journal of Educational Psychology, 92, 202-228.

Mat Daud, N., \& Abu Kassim, N. L. (2011). Examining Student Rating of Teaching Effectiveness using FACETS. J Appl Meas, 12(2), 135-143.

Martilla, J.A., \& James, J.C. (1977) Importance - Performance Analysis. Journal of Marketing, 41(1), 77-79.

McKeachie, W. J. (1979). Student ratings of faculty: A reprise. Academe, 65, 384-397.

Mourkani, G.S., \& Shohoodi, M. (2013). Quality assurance in higher education: Combining internal evaluation and importanceperformance analysis models. Middle East Journal of Scientific Research, 15(5), 643-651.

Muijs, D., \& Reynolds, D. (2002). Teacher beliefs and behaviors: What really matters? Journal of Classroom Interaction, 37(2), 3-15.

Novatorov, E. V. (1997). An importance-performance approach to evaluating internal marketing in a recreation centre. Managing Leisure. 2, 1-16.

O'Neill, M.A., \& Palmer, A. (2004). Importance-Performance Analysis: A Useful Tool for Directing Continuous Quality Improvement in Higher Education. Quality Assurance in Education, 12(1), 39- 52.

Ramli B., Latifah A. L. \& Ng M. S. (2008). Tracking Institutional Performance Using Importance-Satisfaction Analysis. Proceedings of ASAIHL International Conference 2008, Bangkok, Thailand, 7-10 April.

Rial, A., Rial, J., Varela, J. \& Real, E. (2008). An Application of Importance-Performance Analysis (IPA) to the Management of Sport Centres. Managing Leisure, 13(3-4), 179-188.

Richardson, J. (2005) Instruments for obtaining student feedback: a review of the literature. Assessment and evaluation in higher education, 30(4), 387-415.

Riviezzo, A., de Nisco, A., \& Napolitano, M.R. (2009). Importance-performance analysis as a tool in evaluating town centre management effectiveness. International Journal of Retail \& Distribution Management, 37 (9), 748 - 764.

Safavi, S.A., Abu Bakar, K., Ahmad Tarmizi, R., \& Alwi, N.H. (2012). What do higher education instructors consider useful regarding student ratings of instructors? Limitations and recommendations. Procedia - Social and Behavioral Sciences, 31, 653-657.

Siniscalchi, J., Beale, E., \& Fortuna, A. (2008). Using Importance-Performance Analysis to Evaluate Training. Performance Improvement, 47(10), 30-35.

Su. C, S. (2013) An Importance-Performance Analysis of Dining Attributes: A Comparison of Individual and Packaged Tourists in Taiwan. Asia Pacific Journal of Tourism Research, 18(6). 573-597.

Tóth, Zs. E., Jónás, T., Bérces, R., \& Bedzsula, B. (2013). Course Evaluation by Importance-Performance Analysis and Improving Actions at the Budapest University of Technology and Economics. International Journal of Quality and Service Sciences, 5(1), 66-85.

Voss, R., \& Gruber, T. (2006). The Desired Teaching Qualities of Lecturers in Higher Education: A Means End Analysis. Quality Assurance in Education, 14(3), 217 - 242.

Wan Kamaruddin, W.N., \& Ibrahim, M.S. (2010). Enhancing Lecturer Competency of Malaysian Polytechnic Technical Lecturers: A Discrepancy Analysis. Proceedings of the 1stUPI International Conference on Technical and Vocational Education and Training, Bandung, Indonesia, 10-11 November 2010.

Wubbels, T., Levy, J., \& Brekelmans, M. (1997). Paying attention to relationships. Educational Leadership, 54(7), 82-86.

Yu, Y.T, \& Ming, S.H. (2012). Analysis of the Efficiency of Teaching Methods: Using the Variance-Based Method as an Example. The 
Journal of Human Resource and Adult Learning, 8(1), 99-104.

Yusoff, M. (2012). Evaluating business student satisfaction in the Malaysian private educational environment. (Doctoral thesis, Northumbria University, United Kingdom). Available March 23, 2016 from http://nrl.northumbria.ac.uk/7991/1/yusoff_mazirah_ dba-FINAL_BOUND_COPY.pdf

Zimitat, C. (2006, July). First year students' perceptions of the importance of good teaching: Not all things are equal. In Critical Visions. Proceedings of the 29th HERDSA Annual Conference, Western Australia, 10-12 July 2006. 